\title{
An Empirical Evaluation of a Graphics Creation Technique for Blind and Visually Impaired Individuals
}

\begin{abstract}
The representation of pictorial data by people who are blind and sight impaired has gathered momentum with research and development; however, little research has focused on the use of a screen layout to provide people who are blind and sight impaired users with the spatial orientation to create and reuse graphics. This paper contributes an approach to navigating on the screen, manipulating computer graphics, and user-defined images. The technique described in this paper enables features such as zooming, grouping, and drawing by calling primitive and user-defined shapes. It enables blind people to engage and experience drawing and art production on their own. The navigation technique gives an initiative sense of autonomy with compass directions, makes it easy to learn, efficient to manipulate shape with a the simple drawing language and takes less time to complete with system support features. An empirical evaluation was conducted to validate the suitability of SETUP09 technique and to evaluate the accuracy, efficiency of the navigation and drawing techniques proposed. The drawing experiment results confirmed high accuracy (88\%) and efficiency among BVI users.
\end{abstract}




\section{Keywords}

Drawing Technique for Blind people, Blind Drawing Tools, Screen Navigation for Blind and Visually Impaired People, Blind Imagery

\section{Introduction}

The potential of drawing for blind people has been experimented on

Ricciardi, 2009; Ishihara, Takagi, Itoh \& Asakaw, 2006; Kamel \& Landay, 2000;

Kamel \& Landay, 2002; Lambert, Sampaio, Mauss \& Scheiber, 2004) in the past. This work has gathered new momentum with 3D printing (Williams, Zhang, Lo, Gonzales \& D. Baluch, 2014), Hyperbraille (Leo, Cocchi \& Brayda, October 2016), haptic, speech technologies (Zhang, Duerstock \& Wachs, February 2017) and sonification (Walker \& Mauney, March 2010). Research shows that most blind learners often seek the help of a support worker to draw pictures or diagrams, or they avoid drawing because they find it difficult to believe that they would be able to create pictures or diagrams without the guidance from a sighted person and would not even make an attempt. Hence, expressing pictorial thinking for blind users through computers is limited. Subsequently, the need for self-reliant blind drawing techniques and technology has been recognised and highly valued among blind communities.

Most systems previously designed for blind drawing (Kamel \& Landay, 2002; 
Blenkhorn \& Evans, 1998; Calder, Cohen, Landry \& Skaff, 2007; Petrie, Schlieder, Blenkhorn, Evans, A. King, Ioannidis, Gallagher, D. Crombie \& Alafaci, 2002) extract information and display it in objects and associations with sequential-style communication using built- in command buttons. For example, a drawing should enable the user to memorise a floor plan, easily navigate, relocate and backtrack to the original point, and memorise the object arrangement (Hersh, Johnson \& Michael, 2008). The challenge is to develop technologies that are effective and easy to use in producing graphics for the different needs of BVI people's day-to-day lives.

This study introduces a compass-based location tracking approach together with interactive friction gaming text communication styles (games Ltd, 2014) to develop the user's concept of drawing, SETUP09 system demonstrated in Figure 1. An experiment was conducted to evaluate the suitability of command driven drawing technique and virtual navigation system. The system was tested with blind and visually impaired people in the absence of established digital drawing and navigation methods for visually impaired people. Our evaluation of SETUP09 suggests that BVI participants are able to use this navigation and drawing technique with high accuracy and efficiency. SETUP09 enables BVI users to navigate to a particular location and manipulate shapes with confidence, without the assistance of a support worker, and there is a high level of accuracy 
reaching a given location and completing a drawing activity using SETUP09 system.

This paper is structured as follows. In the literature review section, we give a general overview of the mental models of blind and VI people, blind mental imagery, navigation and drawing technologies. In system Introduction section, we explain the proposed system SETUP09 and set out an interaction. In the experiment evaluation section, we discuss the experiment and results. We present our discussion and conclusion in the final section.

\section{Literature Review}

Lack of drawing technologies is a roadblock for students who are blind and visually impaired in the fields of science, technology, engineering, and mathematics (STEM). (Gardner, R.Stewart, Smith \& Tiger, 2002; B.Gould \& Ferrell, 2009). Many technical subjects comprehensively depend on visual materials such as graphs, diagrams and charts that can be unreadable by blind or partially sighted people unless they are introduced in a different format. Understanding visual concepts require comprehension of ideas through 2D images. The idea is to devise a drawing technology for BVI people as a valueadding feature of learning and life in general.

Bornschein and Weber (Bornschein \& Weber, 2017) published a state of art requirement analysis of Digital drawing tools for blind users based on ISO 9241- 
110, Ergonomics of human-system interaction. According to Bornschein, there were many drawing tools that have been experimented in the past, but only a few are used for practical purposes in daily living. Takagi points out that most BVI students and practitioners are in the habit of using tactile maps to recognise highlight-raised line art or objects (N.Takagi, 2009). Some of the tactile graphics tools are InTACT SketchPad $^{\mathrm{i}}$ (inTACT, 2014), Sensational Blackboard ${ }^{\text {ii }}$ (SensationalBooks, 2012), Sewell EZ Write N Draw Raise Line Drawing Kit ${ }^{\mathrm{iii}}$ (MaxiAids, 2019), TactiPad ${ }^{\mathrm{iv}}$ (Sight \& Sound, 2017), Swai Dot Inverter ${ }^{\mathrm{v}}$ and Quick Draw Paper ${ }^{\mathrm{vi}}$. For example, Draftman from APH (school Perkins, 2019) produces simple raised-line graphics to demonstrate math and science concepts, practise handwriting skills, play games such as tic-tac-toe and create art drawings. These analogue drawing drawings can not be digitally stored for later use, or used with other programs or printers, lack system support such as undo, erase, retrieve, feedback and are not efficient or suitable for complex drawing tasks. Some of the experimented digital drawing tools for graph, diagram and drawing production as illustrated in table 1 are SVG-Plott (Bornschein \& Weber, 2017), AGC (Gardner, R.Stewart, Smith \& Tiger, 2002), Maths Class (Cook \& Polgar, 2015), BPLOT2 (Fujiyoshi, Yamaguchi \& Teshima, 2008) and BPLOT3 (Fujiyoshi, Akio, Fujiyoshi, Osawa, KurodaYuta \& Sasaki, 2014), AHEAD (Rassmus-Grohn, Magnusson \& Efiring, 2007), Play with Geometry 
Buzzi, Buzzi, Leporini \& Senette, 2015), Draw and Drag (Grussenmeyer, 2015), TactileView and TactiPad (Huissen, 2016), and many more.

\begin{tabular}{|c|c|c|}
\hline $\begin{array}{l}\text { Name of the } \\
\text { Tool }\end{array}$ & Purpose & Description \\
\hline SVG-Plott & Plot graphs & $\begin{array}{l}\text { Supported by touch and special device input interface } \\
\text { and tactile output without the possibility to access } \\
\text { and check the digital copy before printing. }\end{array}$ \\
\hline $\mathrm{AGC}$ & Plot graphs & Mathematical function plots with sonification feature. \\
\hline Maths Class & Mathematic & $\begin{array}{l}\text { Use of a pin display hardware with a screen reader to } \\
\text { control a graphical maths programme. }\end{array}$ \\
\hline $\begin{array}{l}\text { BPLOT2, } \\
\text { BPLOT3 }\end{array}$ & Line drawing & $\begin{array}{l}\text { Plotter language-based approach, expandable, } \\
\text { complex drawing commands for } \mathrm{x}, \mathrm{y} \text { coordinates. }\end{array}$ \\
\hline AHEAD & Line drawing & $\begin{array}{l}\text { Drawing application with Phantom feedback device } \\
\text { for input and output with touch sensitive overlayer. }\end{array}$ \\
\hline $\begin{array}{l}\text { Play with } \\
\text { Geometry }\end{array}$ & Geometry & $\begin{array}{l}\text { Free hand and touch drawing with sound feedback } \\
\text { TTS and vibration for geometry. }\end{array}$ \\
\hline Draw and Drag & Geometry & $\begin{array}{l}\text { Keyboard and touch drawing with TTS feedback TTS } \\
\text { output for geometry. }\end{array}$ \\
\hline $\begin{array}{l}\text { TactileView } \\
\text { and tactiPad }\end{array}$ & Geometry & $\begin{array}{l}\text { Digital drawing film with wireless pen has direct } \\
\text { tactile output but no actual tactile freehand drawing } \\
\text { feedback. }\end{array}$ \\
\hline Kevin & DFD & $\begin{array}{l}\text { Tabular tactile overlayer with fix set of buttons to } \\
\text { navigate and edit DFD. }\end{array}$ \\
\hline IC2D & Line drawing & $\begin{array}{l}3 \times 3 \text { recursive grid implementation on the screen, } \\
\text { very intuitive. The shapes are limited to system } \\
\text { support shapes. }\end{array}$ \\
\hline
\end{tabular}

Table 1. Comparison of digital drawing tools 
Mental imagery is defined as the human ability to visualise (or construct mental pictures) of various concepts, where the concept can be a simple object or as complex as an entire sentence (Pinker, 1984). It is argued that mental imagery has two properties: the ability to know the properties of an object and the ability to think and reason in the absence of preconceived perception (Kosslyn $\&$ et al, 1990). It was found that blind children outperformed sighted children in both short-term memory and working memory tasks, especially in verbal tasks. Withagen mentions that visually impaired people have superior memory abilities and use serial strategies to outperform the non-existence of visual information, as their minds become more adapted to spatial, sequential and verbal information (Withagen, Kappers, Vervloed, Knoors \& Verhoeven, 2013). Kurniawan also investigated blind users metal/cognitive models in the Windows environment and their coping mechanisms (Kurniawan, Sutcliffe \& Blenkhorn, 2003).It was found that there is a clear relationship between their adaptability to new systems and preconceived mental models. He pointed out that blind users with a structural mental model perceive the desktop environment as strict columns and rows. Users with a functional mental model identify the Windows environment as a set of functions and commands but not its layout information. Some blind users associate both functional commands and structure in the Windows environment. 
Grid-based navigation method was first studied by Kamal (Kamel \& Landay, 2002) and fine-tuning and magnification research was studied by Feng and Zhu (Zhu \& Feng, 2010). Grid-based navigation proved to be highly effective according to the experiment conducted by Kamel and Landay with the introduction to GUESS system and IC2D incorporating a numeric grid-based screen layout, identifying screen areas with numbers for navigation. The gridbased navigation system manoeuvres to an area on the screen without contextual information, using $3 \times 3$ matrix system navigation techniques. The formation of a nine-cell system works well with the intuition of BVI individuals as it is organised in a similar layout to a telephone keypad. Meliones and Sampson (Meliones \& Sampson, 2018) developed an indoor navigation system using floor grid and cardinal direction based turning points, Silva and Wimalaratne (Silva \& Wimalaratne, 2017) used grid-based obstacle localisation using sensors, Kassim (Kassim, Yasuno, Suzuki, H.Jaanfar \& M.Aras, 2016) invented positioning and localisation with a digital compass and direction guiding through voice commands.

We introduce a compass-based navigation and drawing system, which is similar to Kamal's matrix system. The cells are not identified by numbers but by compass directions such as north, south, east, west, north-west, north-east, south-east and south-west. Compass-based navigation also has nine unique points 
in a cell rather than one unique centre point as in the grid-based navigation system and a formal command language operates it. This system is named "SETUP09". The system is designed to navigation on the screen and creating art for educational and general purposes.

\section{Introduction to the system: SETUP09}

Compass-based navigation is derived from grid-based navigation concept but with reformed locations, points reference system with cardinal directions, and implemented with a formal language specification to work with lexical inputs, which is not discussed in this paper. The research aim is targeted to respond to the difficulties of existing technologies by producing a formal language that is consistent and expandable in producing different art, and that supports the communication of floor plan and navigation details to the BVI user effectively. Figure 1 demonstrates the screen division in a $3 \times 3$ grid system using symmetric locations. This is based on compass directions such as north, south, east, west, north- east, north-west, south-east and south-west. It also has the centre region named centre. Each region / location has nine points such as north, south, east, west, centre, north-west, north-east, south-east and south-west. This kind of screen division can be easily comprehended by blind people and enables easy navigation back and forth to different areas and zoom levels. Commands are extracted sequentially and verified as they are read. The figure 2 demonstrates a 
diamond shape drawing with four lines connected to four points on the centre area of the screen.

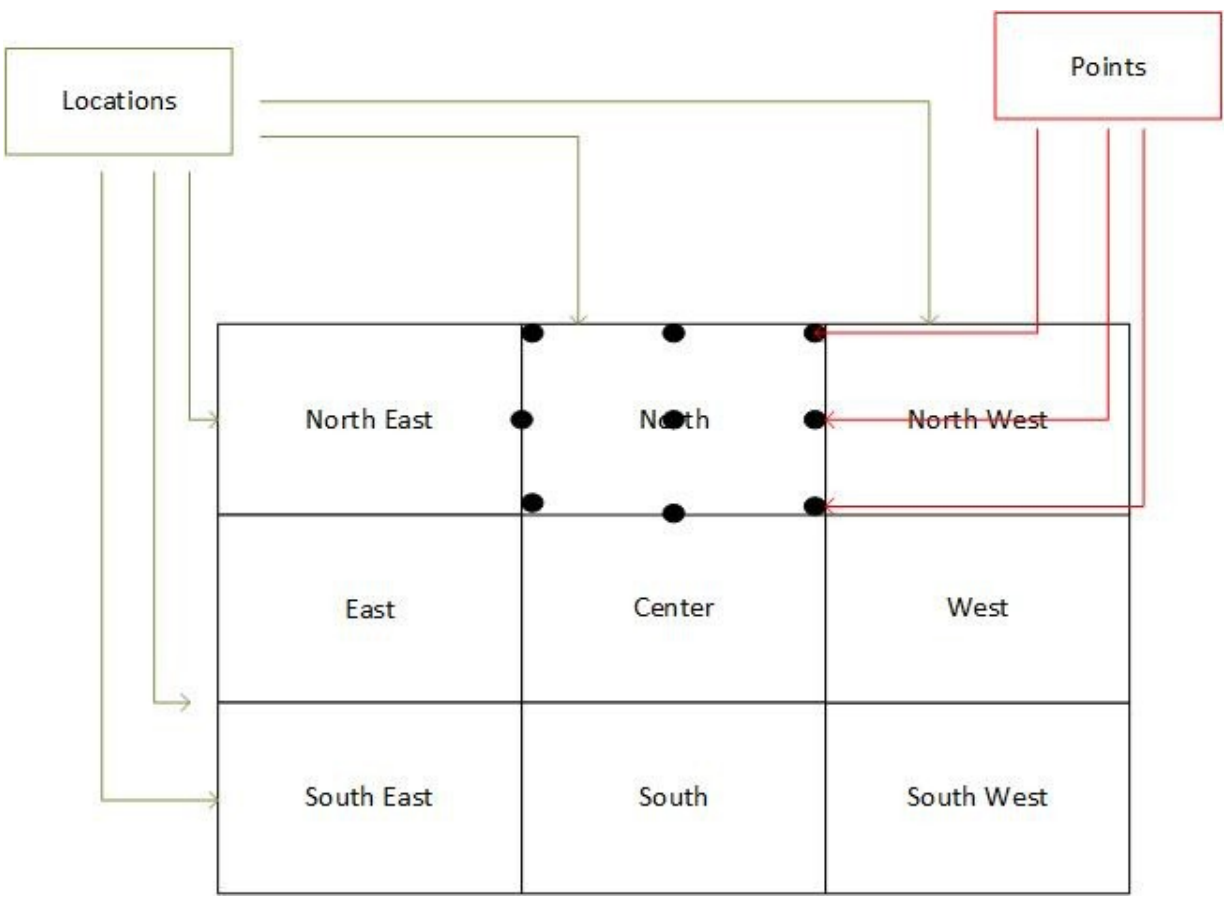

Figure 1. SETUP09 System Interface Layout.

A programming language needs a compiler or interpreter to design its core syntax and semantics (Apple, 2002) in order that the programmer/user can write their programs by calling its commands accommodated by a language. Similarly, SETUP09 is a program that has a programming language to be used by blind 
people in order to produce drawing by calling its commands. The commands enable it to produce art. The detail formal specification is not discussed in this paper.

Using SETUP09 prototype users can enter one or many commands at the user prompt to manipulate an image. For the purpose of this paper, only some commands are discussed. For example:

- To get the focus of an area of a screen: Zoomin [name of the area]

- To extract the focus out of an area: Zoomout

- Users can directly call library objects by their primitive names, such as circle, rectangle, etc.

- A line/lines can be manipulated by calling it: line [point1][point2] or [any number of points]

- A curve/curves can be manipulated by calling it: arc [point1][point2] [point3] or [any number of points]

- A drawing can be defined by giving it a name and a set of commands.

- Users can directly call user-defined objects by their given names, such as mycircle, myrectangle, etc.

- A point on the screen can be assigned to a variable. These variables can be used as a reference point to draw lines and write text. 
- Text can be written on the screen by directly calling a point or user- defined point.

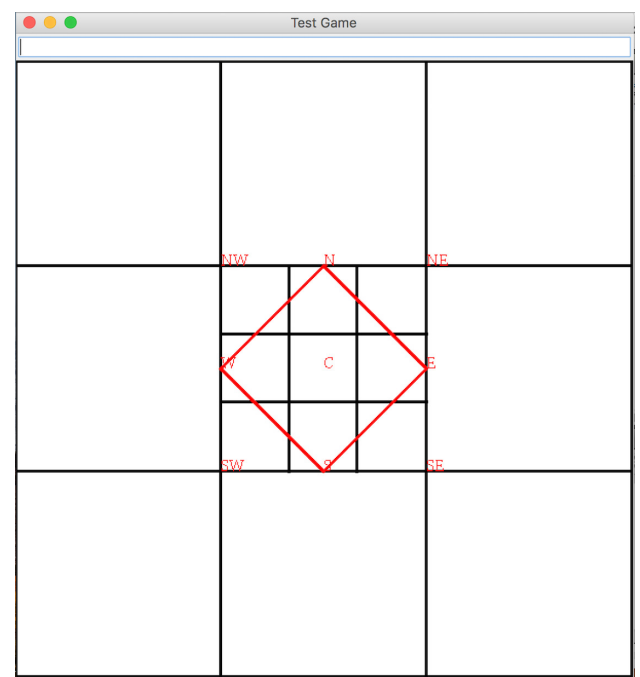

Figure 2. SETUP09 System: Rhombus shape graphic creation on the screen location Centre using points

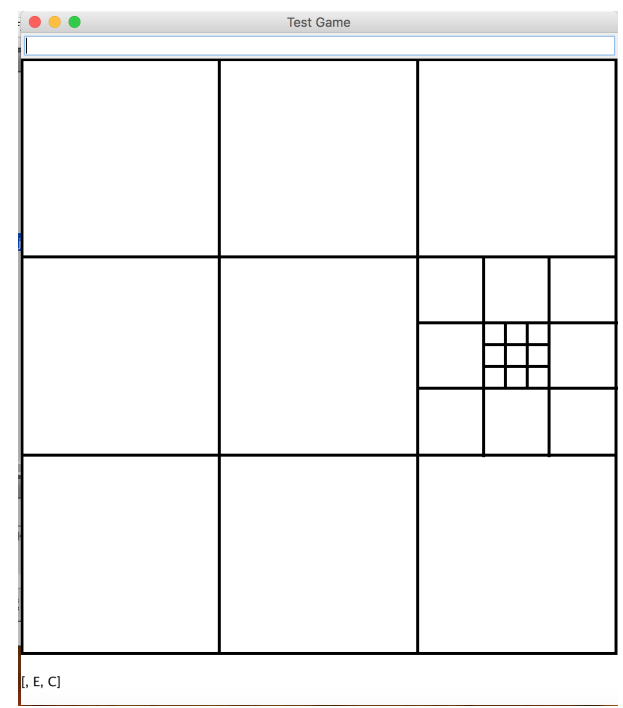

Figure 3. Step 01: Navigation path to East-Centre using arrow keys- Right Arrow key to navigate to East and Alt key to navigate to Centre 


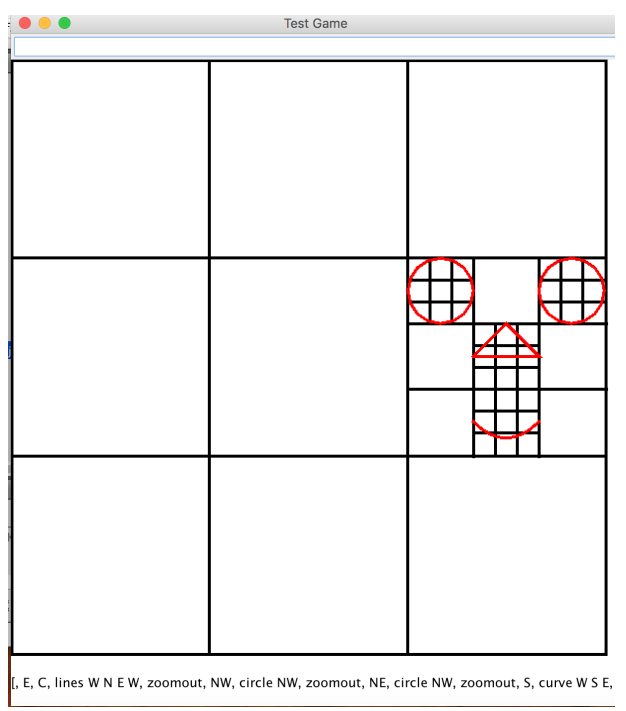

Figure 4. Step 02: Graphics creation on the screen location East using system keyboard keys and shortcut keys to input system commands that is generated on the picture

Figure 3 and 4 demonstrate various steps to create art with system generated shapes. The Input was passed to the system using keyboard shortcut keys, arrow keys and letters. The output was delivered using system produced voice feedback and raised line paper printouts. System commands for figure 4 of face graphics: - E, C, lines W N E W, zoomout, NW, circle NW, zoomout, NE circle NW, zoomout, S, curve W S E.

\section{Experiment and Evaluation}

The experiment was conducted to evaluate the suitability of the command- driven 
drawing technique and virtual navigation system with BVI subjects. A previous study of SETUP09 navigation revealed that blind computer users were able to successfully navigate to screen locations without the help of a support worker (Ohene-Djan \& Fernando, 2018). This study experiments with both drawing and navigation methods and includes three tasks. Participants were collected via contacting different charities for people with blindness or visual impairment. Participants from different age groups and different levels of visual impairment were appointed.

Ten BVI participants were appointed, of whom five were completely blind and predominantly diagnosed with Microphthalmia and Coloboma. All ten BVI participants were registered blind or partially sighted with an average age of twenty-two years old (five males and five females), with a standard deviation of 12.81 and age ranging from 7-49 years. Computer literacy ranges from low to high. Computer literacy was measured by participants' confidence using computers at work, confidence using a keyboard, and confidence using word processing applications. The demographic data is displayed in table 2 .

\section{Apparatus}

The custom experimental system consists of a Mac and Windows operating system, Intel Iris graphics 6100, TTS (text to speech system) and zuyfuse Heater 
with zuyfuse papers to produce tactile images. To ensure higher accuracy in tactile image recognition, we created simple images with thick lines and sufficient space between shapes. The text was produced in Braille letters and English alphabet. The main program consists of a formal language for navigation and drawing, written in Java with 2D library of shapes for image processing. For this experiment, prototype functions are as follows:

- Use hotkey and keyboard input commands

- Navigate to a specific location on the screen

- Create shapes

- Save and label images

- Send images to printer and heater output.

Swell papers were used during the experiment to print haptic images for image recognition tasks. When the paper is subjected to thermal treatment, the dark areas/print create raised relief lines.

\section{Procedure}

This experiment had ten VI participants. We presented each participant with three tasks to complete and measured their performance. Each participant had roughly 30 minutes of training on the system. The training was split across three experimental tasks and included: introduction to SETUP09 and drawing and 
navigation language; familiarity with SETUP09 hotkeys and help keys; handson practice using the prototype and different drawing commands. Audio feedback was provided with help commands. Very few tasks were misunderstood and allowed to be retaken. We observed that blind individuals needed more guidance and explanation than partially sighted individuals.

\section{Instructed drawing}

We gave participants printed swell papers containing shapes of triangles one inside the other with two zoom sizes. We then asked participants to draw the given simple images (triangles in figure 5, house in figure 6, diagram in figure 7) using SETUP09 precisely as was on the swell papers. Then we printed produced output using swell papers to compare the original and reproduced drawings. Upon completion, we asked them to describe the whole picture. We recorded $100 \%$ accuracy for producing a given image with no difference; $90 \%$ accuracy for producing a given image with $1-2$ errors; $80 \%$ accuracy for

producing the given image with 3-4 errors; and 40\% for producing 5-10 errors during image creation,

e.g. navigation to incorrect location, referring to incorrect points, calling incorrect shapes, incorrect input commands and input command errors which have added extra time for completion. Errors were mainly due to forgetting 
commands and lack of prior system prior use knowledge. The purpose of Instructed drawing task was to find out the participants' ability to reproduce system images with accurate recognition of shapes, locations and sizes.

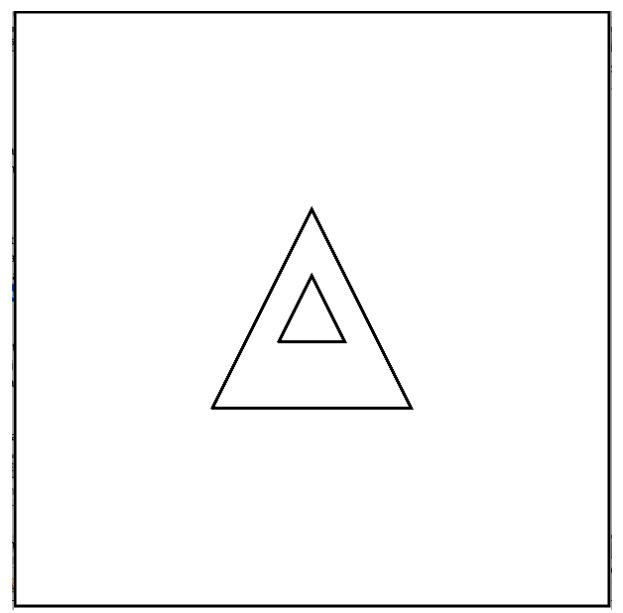

Figure 5. Task 01 activity of Instructed Drawing (a) triangles

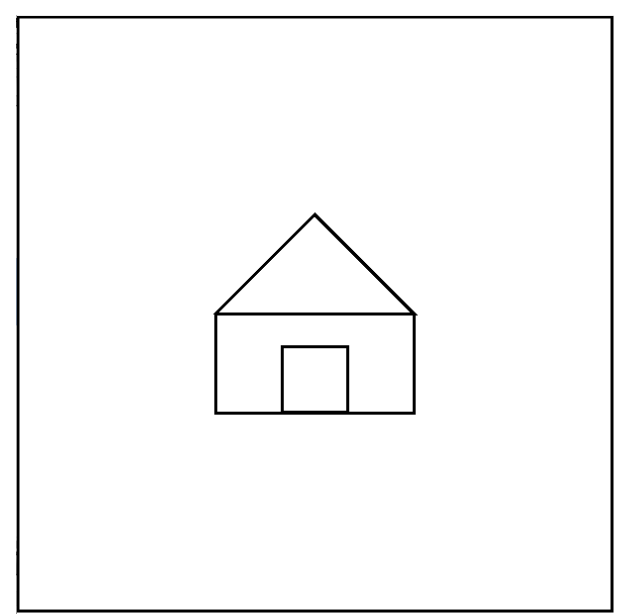

Figure 6. Task 01 activities of Instructed Drawing (b) a house 


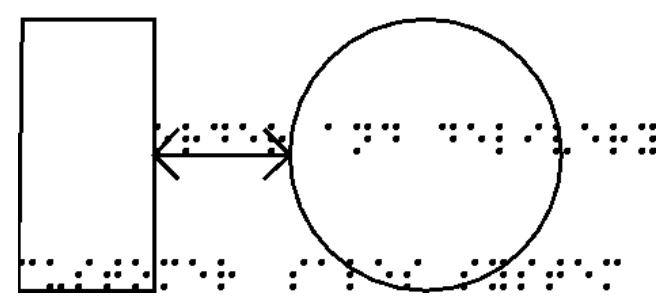

Figure 7. Task 01 activity of Instructed Drawing (c) a diagram

\section{Non-instructed drawing}

We asked participants to imagine a single shape and an image in a selected screen location with a selected zoom layer of their own choice. We asked them to describe the whole picture. We then recorded their mental image as they explained it verbally before they produced the imagined shape using SETUP09. The image was printed after the end of each task using swell paper to compare it with the original idea. We recorded the accuracy of the user-produced image based on the prior recording (example images are demonstrated in figure 11). The purpose of Non-instructed drawing was to find out the participants' ability to produce non-guided shapes with accuracy and efficiency. 


\section{Image recognition}

In the final task, we presented participants with three system-produced images and diagrams. e.g. a square in figure 8 , a table in figure 9 and a flowchart in figure 10 . We gave one image at a time on swell papers asking them to explore and verbally describe the images. We categorised results into three different areas: "Full Rec", "All Shapes Rec" and "Some Shape Rec". "Full Rec" symbolises participants' ability to recognise all shapes and recognising the name of the image, where "All Shapes Rec" symbolises participants' ability to recognise all shapes without naming the image. "Some Shape Rec" symbolises participants' ability to recognise some shapes presented in the image. The purpose of Task 03 was to find out if BVI individuals accurately perceive systemproduced art and spatial representation of screen images.

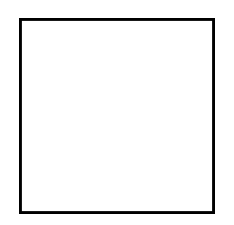

Figure 8. Task 03: Square presented for image recognition Task 


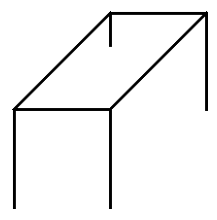

Figure 9. Task 03: Table Images presented for image recognition Task

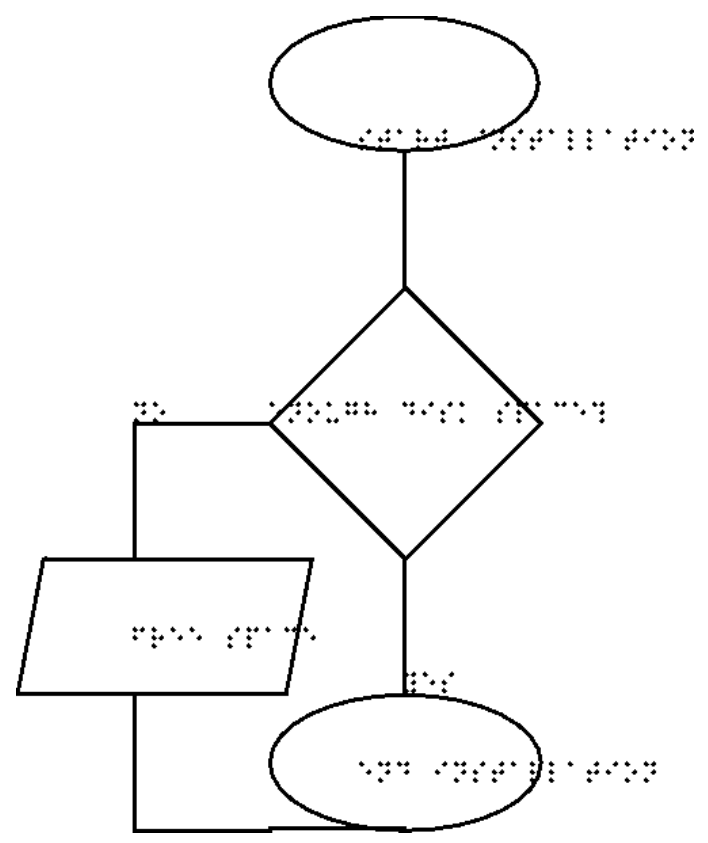

Figure 10. Task 03: Diagram presented for image recognition Task

\section{Experiment design}

The drawing and navigation study consisted of instructed drawing, noninstructed drawing and image recognition activities with the user groups as a subject factor (Blind and VI), task phase as a within-subject factor (instructed, 
non-instructed, recognition). The study uses SETUP09 prototype and systemproduced swell images for all three tasks and its activities. We derived the following hypothesis:

1. H1: SETUP09 2D drawing technique is an efficient drawing technique to draw images for BVI individuals.

2. H2: SETUP09 2D drawing technique can accurately reproduce mental images of BVI individuals.

3. H3: SETUP09 2D system-produced tactile images are accurately perceived by BVI individuals.

\begin{tabular}{|c|c|c|c|c|c|c|c|}
\hline Participant & Gender & Age & $\begin{array}{l}\text { Reason of } \\
\text { Blindness }\end{array}$ & $\begin{array}{l}\text { Residual } \\
\text { vision }\end{array}$ & $\begin{array}{c}\text { Age of } \\
\text { Blindness }\end{array}$ & Education & $\begin{array}{l}\text { Computer } \\
\text { literacy }\end{array}$ \\
\hline $\mathrm{P} 1$ & $\mathrm{M}$ & 26 & Microphthalmia & None & Birth & Graduate & High \\
\hline $\mathrm{P} 2$ & $\mathrm{~F}$ & 21 & Microphthalmia & None & Birth & $\begin{array}{l}\text { School } \\
\text { leaver }\end{array}$ & High \\
\hline P3 & M & 15 & $\begin{array}{l}\text { Microphthalmia } \\
\text { and Coloboma }\end{array}$ & $\begin{array}{c}\text { Faint } \\
\text { light/darks } \\
\text { and some } \\
\text { shapes } \\
\end{array}$ & Birth & Student & High \\
\hline P4 & M & 10 & $\begin{array}{l}\text { Microphthalmia } \\
\text { and Coloboma }\end{array}$ & $\begin{array}{c}\text { Faint } \\
\text { light/darks } \\
\text { and some } \\
\text { shapes } \\
\end{array}$ & Birth & Student & Moderate \\
\hline P5 & M & 37 & $\begin{array}{l}\text { Microphthalmia } \\
\text { and Coloboma }\end{array}$ & None & Birth & $\begin{array}{l}\text { School } \\
\text { leaver }\end{array}$ & High \\
\hline P6 & $\mathrm{F}$ & 20 & $\begin{array}{l}\text { Microphthalmia } \\
\text { and } \\
\text { Anophthalmia }\end{array}$ & None & Birth & $\begin{array}{l}\text { School } \\
\text { leaver }\end{array}$ & Low \\
\hline P7 & M & 14 & $\begin{array}{l}\text { Microphthalmia } \\
\text { and Coloboma }\end{array}$ & None & Birth & Student & High \\
\hline P8 & $\mathrm{F}$ & 7 & $\begin{array}{l}\text { Microphthalmia } \\
\text { and Coloboma }\end{array}$ & $\begin{array}{c}\text { Faint } \\
\text { light/darks } \\
\text { and some } \\
\text { shapes }\end{array}$ & Birth & Student & Moderate \\
\hline
\end{tabular}




\begin{tabular}{|c|c|c|c|c|c|c|c|} 
P9 & F & 49 & $\begin{array}{c}\text { Glaucoma and } \\
\text { Microphthalmia }\end{array}$ & $\begin{array}{c}\text { Faint } \\
\text { light/darks }\end{array}$ & Birth & $\begin{array}{c}\text { School } \\
\text { leaver }\end{array}$ & Low \\
\hline P10 & F & 27 & $\begin{array}{c}\text { Cortical visual } \\
\text { impairment }\end{array}$ & $\begin{array}{c}\text { Faint } \\
\text { light/darks } \\
\text { and some } \\
\text { shapes }\end{array}$ & Birth & $\begin{array}{c}\text { School } \\
\text { leaver }\end{array}$ & High \\
\hline
\end{tabular}

Table 2. Information on the congenitally blind participants of the experiment

\section{Performance measure and data analysis}

1. H1 hypothesis (SETUP09 2D drawing technique produces accurate mental images as conceived by BVI individuals) was measured by an instructed drawing (task 1 activities) accessing participants' ability to efficiently complete a given task within a reasonable time.

2. H2 hypothesis (SETUP09 2D drawing technique can accurately reproduce mental images of BVI individuals) was measured by the non-instructed drawing (task 2 activities) accessing participants' ability to efficiently complete an intended drawing task against recorded drawing.

3. H3 hypothesis (SETUP09 2D system-produced tactile images are accurately perceived by BVI individuals) was measured by the image recognition task (task 3 activities) accessing participants' ability to efficiently recognise system-produced images.

During non-instructed drawing, BVI individuals spoke about shapes, location and size of their mental model prior to the activity that was recorded at the beginning, and then the system-printed swell images were 
used to crosscheck their art against the original idea. A score was given for the actual drawing against intended drawings. The IBM usability questionnaire with seven-point scale was used to access participants' perception of system suitability, ease of use and cognition, James (1993).

\section{Data Analysis}

Times were recorded for all three tasks using a stopwatch. We collected data from ten BVI participants. The first task had three activities, the second task had two activities, and task three had three activities each. Two blocks of three trials and one block of two trials were collected from then participants for a total of $(10 * 3 * 2)+(10 * 2)=80$ trials were recorded with accuracy, errors and efficiency. Six attempts had to be redone due to the confusion of instruction and it was as requested by participants themselves. Four erroneously recorded trails needed repeating.

\section{Results}

For all three tasks, instructed drawing, non-instructed drawing and image recognition, we cover performance with an examination of the variations between different groups and (blind and partially sighted), phases (activities). We have taken full performance time length, which includes time taken for errors. Time was recorded from the start of the system use until the end of a task. 


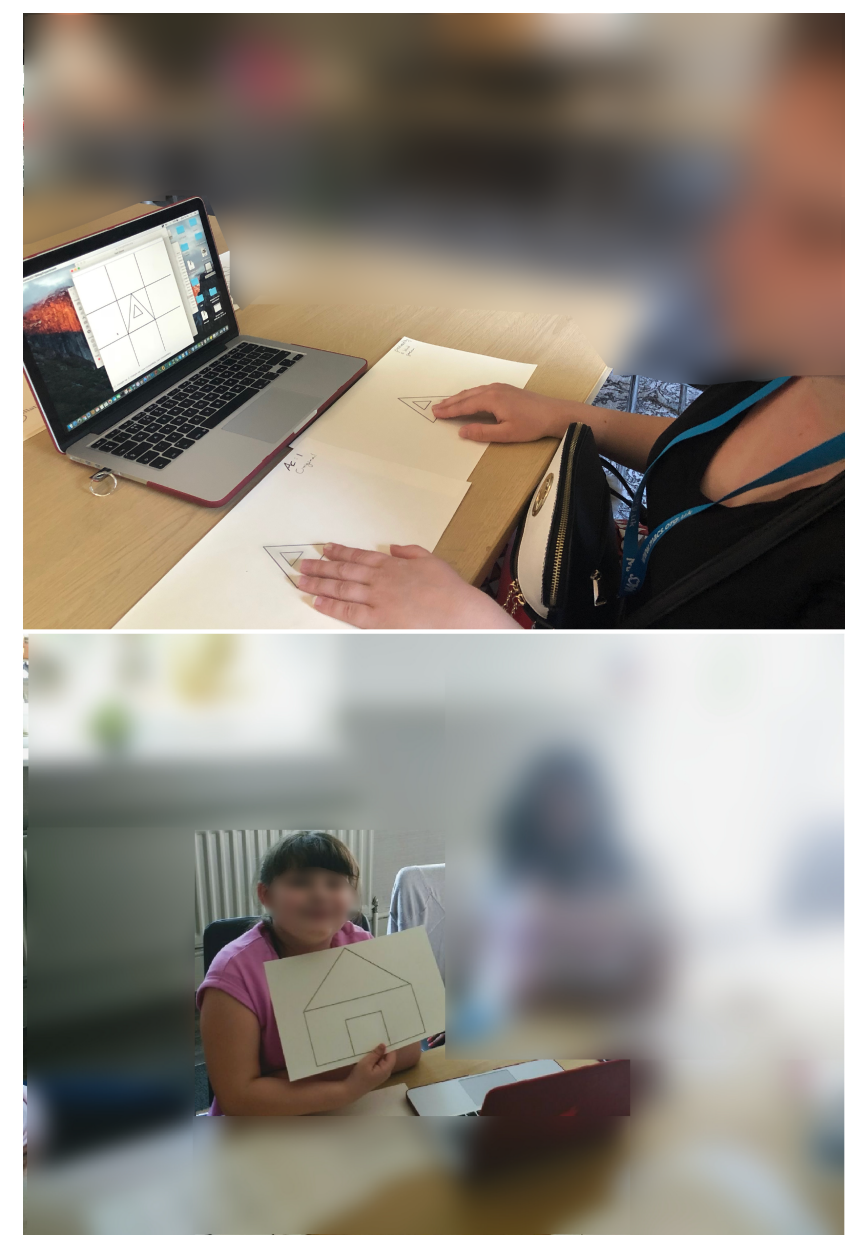

Figure 11. Demonstrates images captured during the experiment-performing task 01 


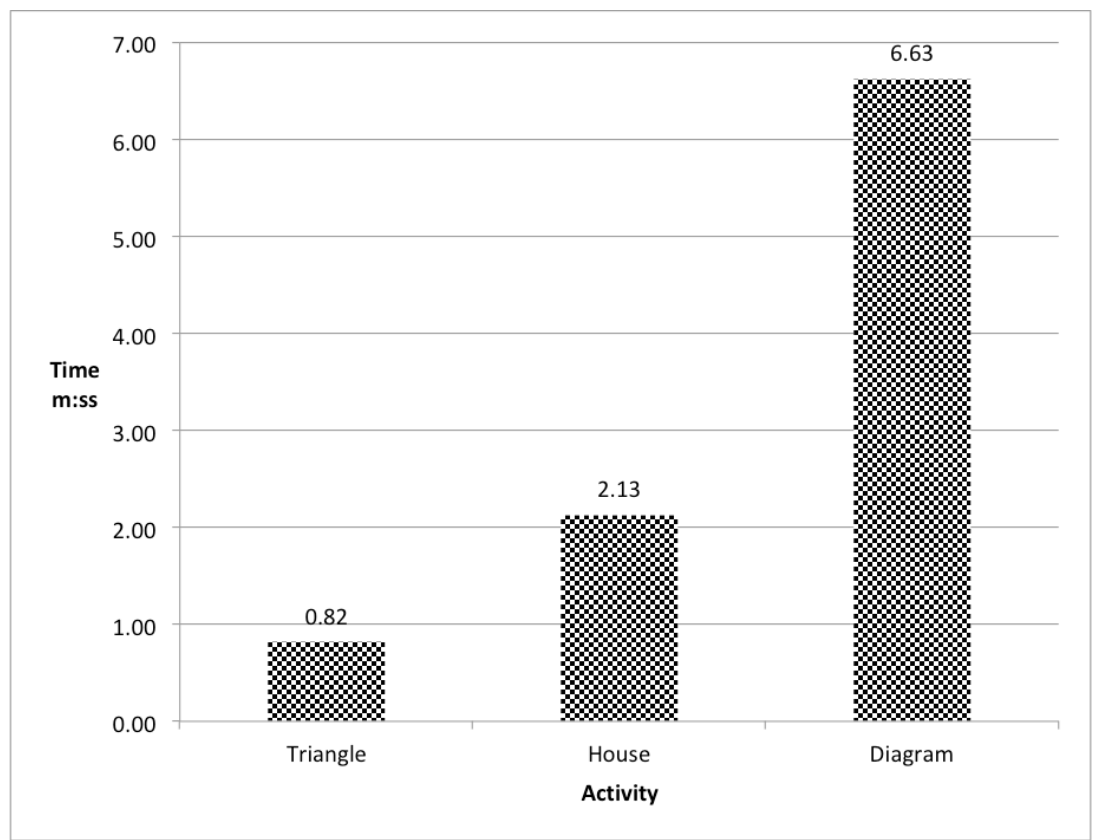

Figure 12. Instructed drawing: Average task completion time on the task 1 activities for both blind and VI participants

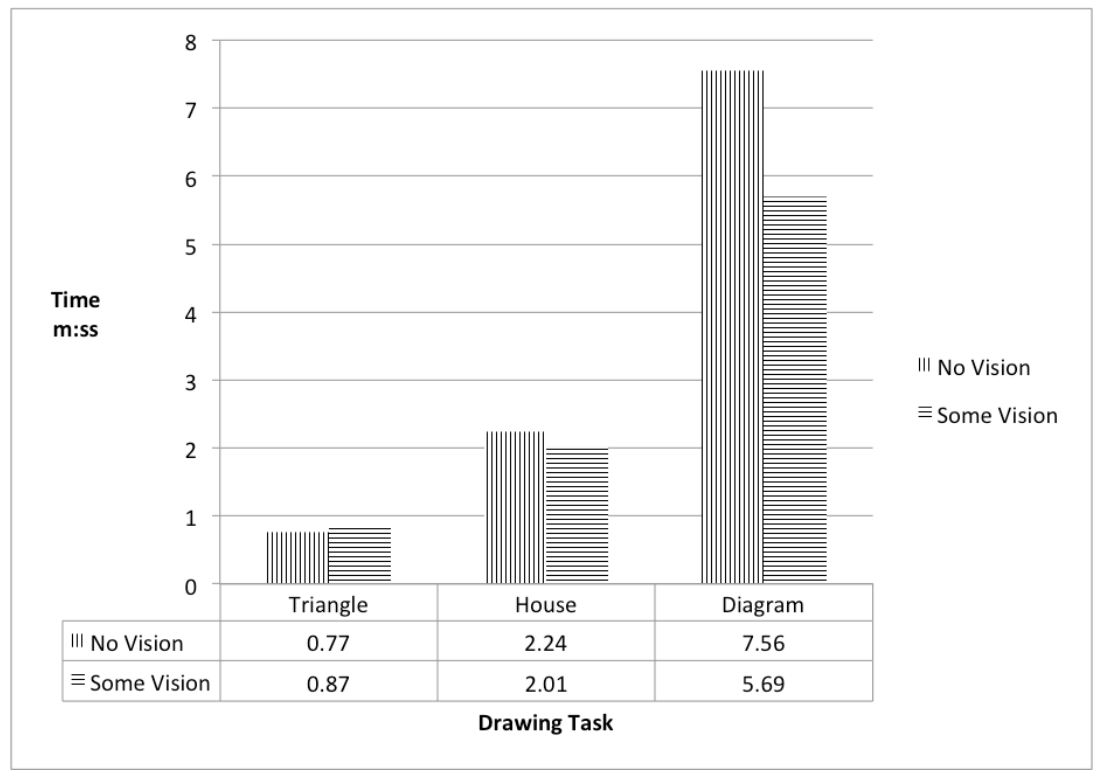

Figure 13. Instructed drawing: Average task completion time based on participants' vision 


\section{Instructed drawing: H1}

The performance was measured on time taken; errors made and output accuracy by examining shapes, locations, and sizes. Figure 12 bar chart illustrates the times taken to draw instructed drawing task. Figure 13 illustrate the variation of data among different cohorts. The average completion time of a shapedrawing task by the blind group was

$0.77(\mathrm{SD}=0.64 \mathrm{~s})$, and VI groups was $0.87 \mathrm{~s}(\mathrm{SD}=0.81 \mathrm{~s})$. We found $\mathrm{P}$ value $=0.83$. The average completion time of an image-drawing task by the blind group was $2.24 \mathrm{~s}(\mathrm{SD}=1.20 \mathrm{~s})$ and VI group $2.01 \mathrm{~s}(\mathrm{SD}=1.37 \mathrm{~s})$. We found $\mathrm{P}$ value $=0.77$. The average completion time of a diagram-drawing task by Blind group was 7.56s $(\mathrm{SD}=2.37 \mathrm{~s})$ and VI groups was $5.69 \mathrm{~s}(\mathrm{SD}=1.87 \mathrm{~s})$. We found $\mathrm{P}$ value $=0.20$. The completion time difference between groups was not statistically significant.

The BVI participants completed simple tasks, but found it challenging to complete more complex tasks such as diagrams. All of them completed the shape (triangles) and image (house) activity with 100\% accuracy but 8/10 participants managed to get $80 \%$ or more of the diagram completion. Completion was highly correlated with the difficulty of the task.

BVI participants accurately produced the given shapes (shape, diagram and image) with $77 \%$ accuracy. The diagram drawing activity reported to consume more time (mean=6.72 m:ss).The difficulty was mainly due to insufficient 
previous system practice with navigation steps across the screen and with in different zoom levels.

Supporting H1, errors made, accuracy and completion time were taken as indicators of the efficiency of the system. The above data demonstrates that blind participants performed better in the shape activities, but not with image and diagram drawing. However, the performance of both groups was not statistically significant based on previously cited P values. Some BVI users reported a longer time to complete tasks due to several factors including limited confidence, limited ability and limited computer use.

Non-Instructed drawing: H2

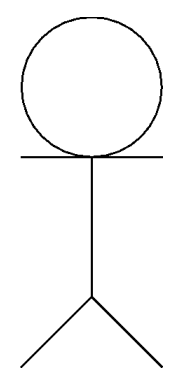

Figure 14. Task 02 Non-Instructed Drawing: A stickman produced by a VI participant

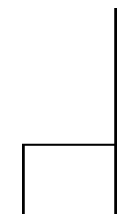

15. Task 02 Non-Instructed Drawing: A chair produced by a blind participant 
The performance was measured on time taken, errors made, output accuracy by examining shapes, locations and size. Participants were asked to draw a shape and an image of their choice without giving any instruction. Their initial ideas were recorded to check the accuracy of the task. Figure 16 bar chart demonstrate average times taken for non-instructed drawings. Participants produced different types of images such as in figure 14 images of a stickman and a chair in the figure 15 are two examples. The average time taken to draw a shape for blind users were mean $=0.57, \mathrm{SD}=0.53 \mathrm{~m}: \mathrm{ss}$ comparing to VI users were recorded with the mean $=0.34$ and $\mathrm{SD}=0.11 \mathrm{~m}$ :s. The difference was not statistically significant during non-instructed shape drawing $(\mathrm{p}=0.38)$. The average completion time of an image-drawing task by blind users was $2.10 \mathrm{~s}(\mathrm{SD}=0.68 \mathrm{~m}: \mathrm{s})$ and VI users reported the mean of $2.02 \mathrm{~m}: \mathrm{ss}$ and $(\mathrm{SD}=0.70)$. The difference between two groups was not statistically significant $(\mathrm{p}=0.85)$.

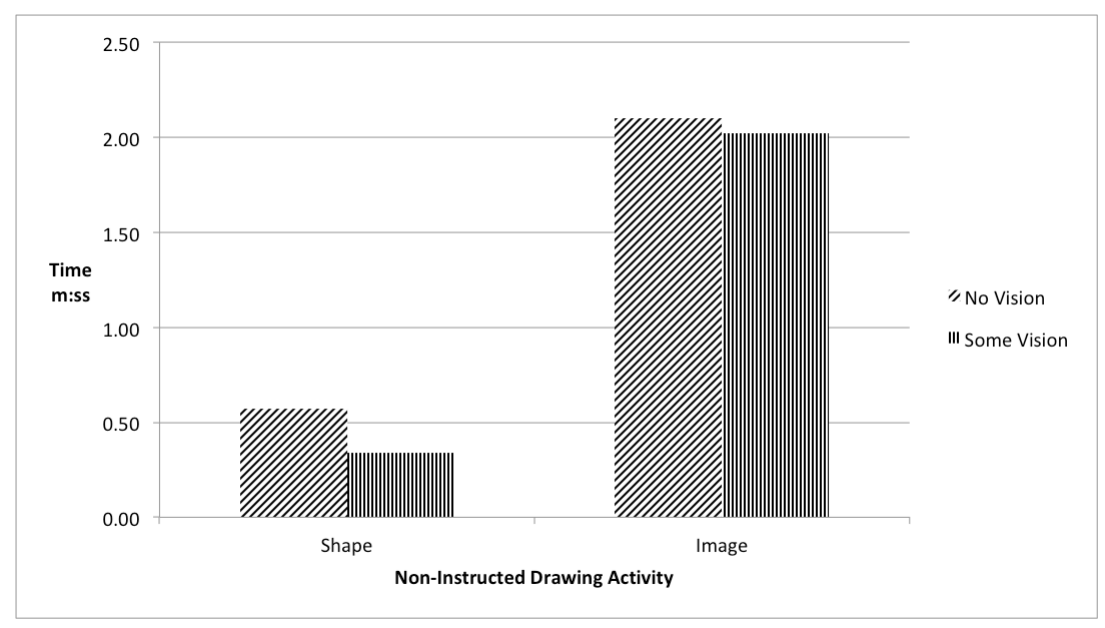


Figure 16. Task 02: Completion time of non-instructed drawing based on vision

Figure 17 visualises the errors made during Task 02, non-instructed drawing. Errors were mainly due to forgetting commands and lack of prior system knowledge. Blind participants completed $70 \%$ of trials without errors and VI participants completed $90 \%$ of trials without errors.

Figure 18 demonstrate that both blind and VI participants completed the planned/recorded drawing and stayed with the task until completion. They also had more practice of the system from instructed drawing task. They produced shapes and images with $100 \%$ accuracy with an average of 1.26 (m:ss). The difference of two groups was not statistically significant.

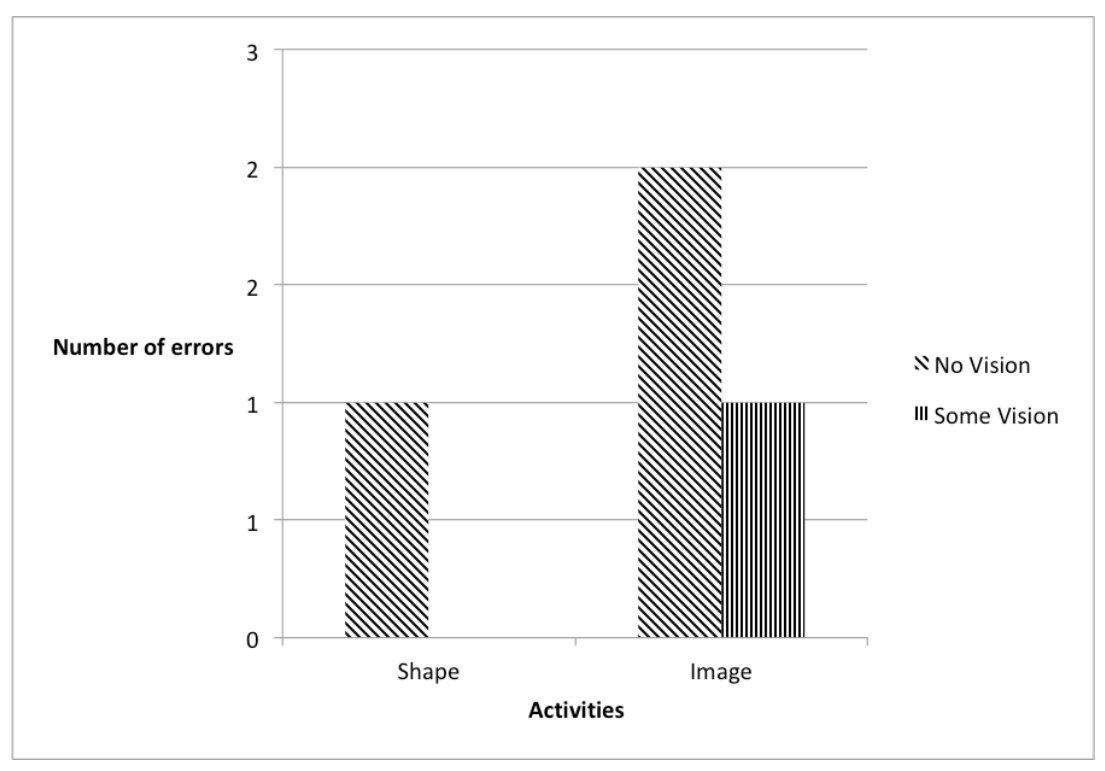


Figure 17. Task 02: Completion time of non-instructed drawing based on vision

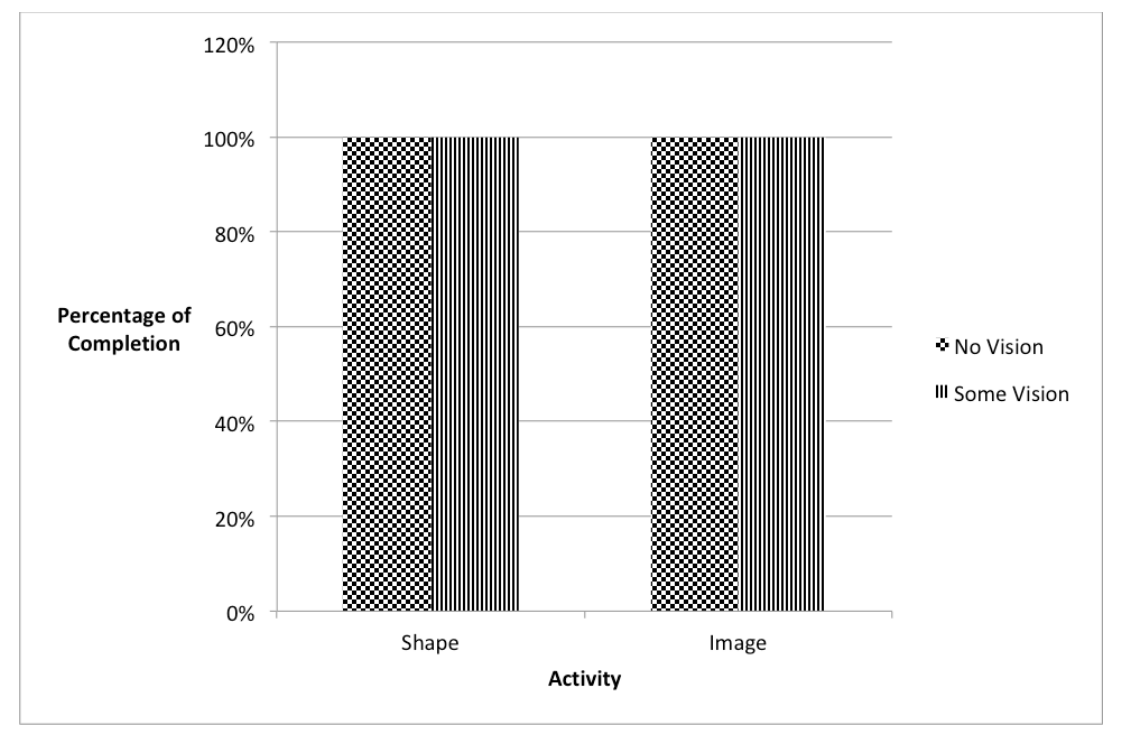

Figure 18. Task 02: Completion time of non-instructed drawing based on vision

Supporting H2, accuracy and errors made were taken as indicators of SETUP09 drawing technique's ability to accurately reproduce mental images of BVI individuals. The above data demonstrate that partially sighted participants were the leading performers in terms of speed of completion. However, both groups reported $100 \%$ accuracy of creating their preconceived mental images using SETUP09. The VI group made fewer errors compared to their blind counterparts. 


\section{Image recognition: $\mathrm{H3}$}

The performance was measured on time taken to recognise shapes, locations and sizes.

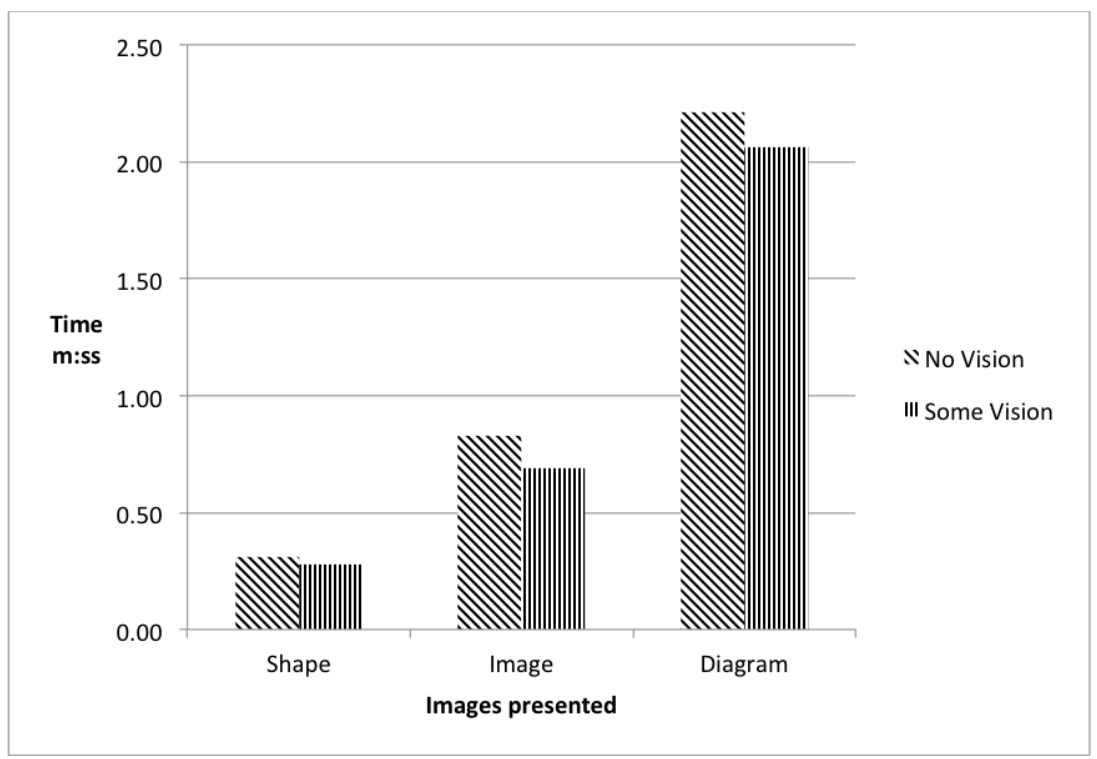

Figure 19. Image Recognition Time by BVI groups

The average recognition time taken to recognise a shape in the figure 8 (Square) task by blind participants was $0.31 \mathrm{~s}(\mathrm{SD}=0.08 \mathrm{~s})$ and VI participants was $0.28 \mathrm{~s}$ $(\mathrm{SD}=0.09 \mathrm{~s})$ as demonstrated in bar chart 19 . We found $\mathrm{P}$ value $=0.59$ between different groups, which means difference of groups' performance, is not significant. The average recognition time of an image in the figure 9 (table) recognition task by blind users was $0.83 \mathrm{~s}(\mathrm{SD}=0.56 \mathrm{~s})$ and VI participants were $0.69 \mathrm{~s}(\mathrm{SD}=0.09 \mathrm{~s})$. The difference between groups was not statistically significant. 
We found $\mathrm{P}$ value $=0.71$ between groups. The average recognition time taken to recognise a diagram in the figure 10 tasks by blind participants was $2.21 \mathrm{~s}$ $(\mathrm{SD}=0.573 \mathrm{~s})$ and VI participants was $2.06 \mathrm{~s}(\mathrm{SD}=1.17 \mathrm{~s})$. We found $\mathrm{P}$ value $=0.80$. VI participants were more efficient in identifying images and diagrams than blind participants. Most BVI participants have never attempted to study or draw flowcharts due to the complexity of visual details. However, both blind and VI participants managed to recognise individual shapes with high accuracy.

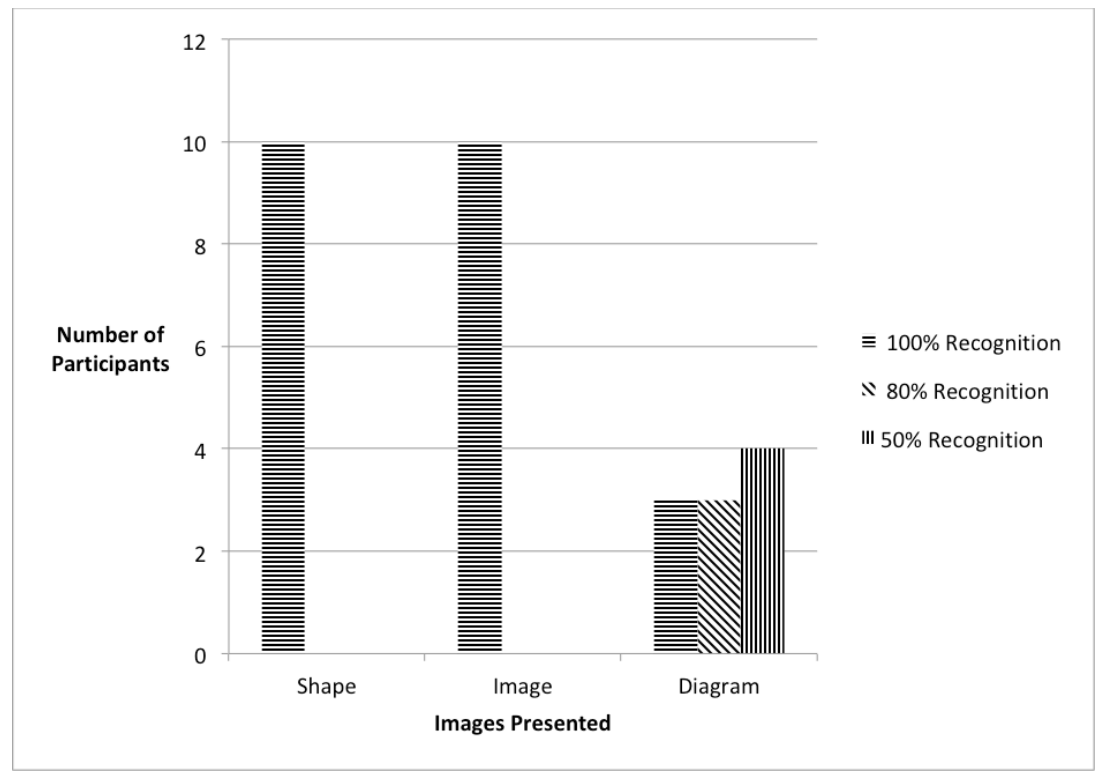

Figure 20. Accuracy of task 03: Image Recognition

Both blind and VI individuals managed to identify shape and image with $100 \%$ accuracy. Identification of diagrams was challenging as illustrated in bar chart 20. Overall it took less than a minute on average to recognise a given shape or 
image (0.43s) and took longer to recognise a diagram (2.14s). Recognition of diagrams was challenging due to the necessary pre-requisite knowledge of concepts such as flowcharts.

Supporting H3, accuracy and recognition percentage were taken as indicators to measure the ability to perceive system-produced tactile images. The above data demonstrates that blind participants were the leading performers when it came to the recognition task. However, both groups reported over $77 \%$ of full recognition of system-produced shapes, images or diagrams. In fact, all blind and VI participants continually recognised shapes $(100 \%)$ of the presented images. Based on the findings above, the difference in-group performance in the recognition task is not statistically significant.

\section{The post SETUP09 questionnaire}

The post SETUP09 questionnaire is reporting Cronbach's alpha value as 0.79 of scale reliability with acceptable internal consistency, mean $=2.06$ and $\mathrm{SD}=1.03$. All participants who completed all 3 tasks successfully also completed post SETUP09 task questions. Level 1 signifies agreeing strongly and Level 7 signifies disagreeing strongly with questions asked. Five questions were posed at the end of three tasks. We asked all participants to give ratings for five different qualitative measures of system SETUP09 as set out in figure 21 . 


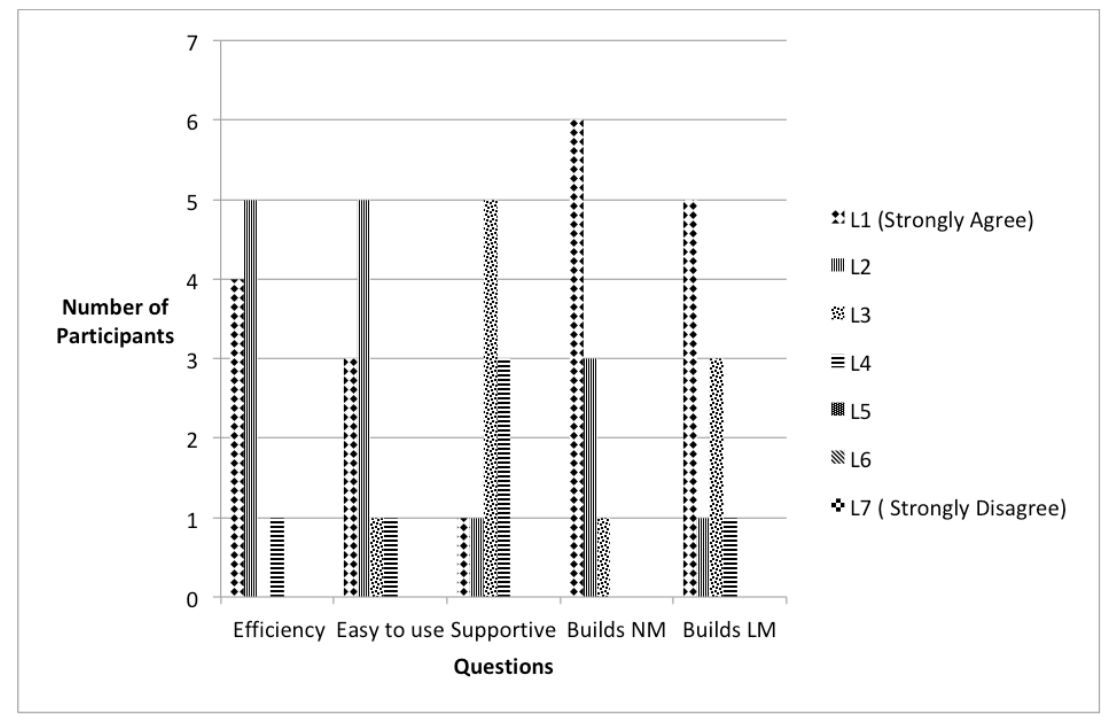

Figure 21. Subjective Data analysis of participants' answers to post study questions

1. (Q1) SETUP09 is efficient.

2. (Q2) SETUP09 is easy to use.

3. (Q3) SETUP09 is supportive.

4. (Q4) SETUP09 builds a navigation model in participant's mind.

5. (Q5) SETUP09 builds a layout model in the participant's mind. 


\begin{tabular}{|c|c|c|c|c|c|c|}
\hline Participant & Vision & Efficiency & $\begin{array}{c}\text { Easy to } \\
\text { use }\end{array}$ & Supportive & $\begin{array}{c}\text { Builds } \\
\text { NM }\end{array}$ & $\begin{array}{c}\text { Builds } \\
\text { LM }\end{array}$ \\
\hline $\mathrm{P} 1$ & No Vision & 1 & 1 & 3 & 1 & 1 \\
\hline $\mathrm{P} 2$ & No Vision & 2 & 1 & 1 & 1 & 1 \\
\hline P5 & No Vision & 1 & 2 & 2 & 1 & 3 \\
\hline $\mathrm{P} 6$ & No Vision & 2 & 2 & 3 & 1 & 2 \\
\hline P7 & No Vision & 2 & 2 & 3 & 2 & 1 \\
\hline P3 & $\begin{array}{l}\text { Some } \\
\text { Vision }\end{array}$ & 4 & 3 & 4 & 1 & 3 \\
\hline $\mathrm{P} 4$ & $\begin{array}{l}\text { Some } \\
\text { Vision }\end{array}$ & 2 & 2 & 3 & 2 & 3 \\
\hline P8 & $\begin{array}{c}\text { Some } \\
\text { Vision }\end{array}$ & 1 & 2 & 3 & 2 & 1 \\
\hline P9 & $\begin{array}{l}\text { Some } \\
\text { Vision }\end{array}$ & 2 & 4 & 4 & 3 & 4 \\
\hline P10 & $\begin{array}{l}\text { Some } \\
\text { Vision }\end{array}$ & 1 & 1 & 4 & 1 & 1 \\
\hline
\end{tabular}

Table 3. Subjective Data analysis of participants' answers to post study questions

Levels one and two are predominantly selected by the majority of participants with the exception of the question about the supportiveness of the system. 9/10 participants agreed that SETUP 09 technique is efficient and the technique builds a navigational model in participants' minds by selecting levels 1 and 2 of the Likert scale; 8/10 participants agreed that the SETUP09 technique is easy to use. 6/10 strongly agreed that SETUP09 technique builds a navigational model in participants' mind.

However, the majority of participants thought that the system could be more supportive in terms of error detection, correction, input and output functionalities. The data table 3 demonstrates that participants with no vision 
predominantly selected Levels 1 and 2 of the Likert scale, whereas participants with some vision thought the prototype could be further improved to accommodate partially sighted people. Two-Way ANOVA gives P-value of 0.0045 which is $\mathrm{P}<0.05$, and demonstrates that there is a difference between the post-experiment feedbacks of the two groups (no vision vs. partial vision participants). The participants who had no ision highly agreed with questions than participants who were visually impaired. Lots of blind and VI participants agreed that enough time for system familiarisation is the key to confidence and efficiency. Some participants didn't like the system voice feedback feature as it added further delay in processing commands. Hence some suggested shorter audio feedback clips and auto-corrective text as mentioned in table 4.

\begin{tabular}{|l|l|}
\hline Vision & Views of the participants \\
\hline No Vision & $\begin{array}{l}\text { The compass system is very intuitive, I can visualise the art I } \\
\text { produce, this is helpful for schools with VI students, waiting time } \\
\text { for the system feedback seems to be obstructive, many grids on } \\
\text { printed paper is difficult to read, different levels of system feedback } \\
\text { is needed, more time is required to get used to the system, tactile } \\
\text { gridpad for such a system is a useful tool. }\end{array}$ \\
\hline Some Vision & $\begin{array}{l}\text { The system is effective and interesting. I like if the software corrects } \\
\text { typing errors, the bigger text is required for people with low } \\
\text { vision and lines with different thickness, system interaction could be } \\
\text { faster, ability to change system voice and auto text correction } \\
\text { facility is needed. }\end{array}$ \\
\hline
\end{tabular}

Table 4. Personal views of the participants 


\section{Discussion and Conclusion}

An experiment was conducted to evaluate the suitability of a command- driven drawing technique and virtual navigation system with blind and VI participants in the absence of established drawing and navigation methods for BVI computer users. The system SETUP09 was driven by a set of language commands for navigation and shapes creation, for blind and VI participants. Blind cohort's performance time and VI counterparts' performance times were similar in this experiment and this did not reach significance. Our basic observation of SETUP09 is that, it is a suitable and reliable technique, which helps to minimise the trials in the effort, time, and resources to navigate on the screen and produce art.

Tasks of instructed drawing, non-instructed drawing and image recognition were given to be performed using the SETUP09 system at the start. The results demonstrate that SETUP09 navigation and drawing technique is not only efficient among VI participants but also far more efficient among blind participants. Blind participants took a mean time of

2.01 (m:ss) to draw a shape/image where VI participants took a mean time of 1.31 (m:ss). It was evidenced that the low level of confidence, slowness of learning, low levels of computer literacy and efficiency impacted some participants' ability 
with longer performance times. On the other hand, the blind cohort was thorough, closely followed instructions and performed well in all task.

We believe that increased training and learning time of the system technique and commands could produce equal or better performance with the group. Instructed and non-instructed drawing tasks have no significant difference among group performance time. The results confirmed that Blind individuals took slightly longer to complete some tasks than VI individuals.

In support of $\mathrm{H} 1, \mathrm{H} 2$ and $\mathrm{H} 3$, the results confirmed that blind participants are showing competitive and similar performance compared to VI participants with high accuracy, completion and fewer errors in all of the assigned tasks. More than $88 \%$ of trials reported with $100 \%$ accuracy of given tasks $1-2$ among BVI participants. Almost all drawing activities were completed with an average time of 1.35 (m:ss), apart from the diagram-drawing task. $90 \%$ of the participants strongly agreed that the system was efficient and builds a navigation model. Overall, BVI participants demonstrated their drive and motivation to manipulate graphics independently without any help of a support worker. In general, VI participants were marginally faster when with drawing tasks. We also studied the gap between the confidence and ability of technology and computer use among different groups and ages. Better self-awareness for people with different visual impairments can be achieved with the system facility for contrasting 
outputs: different text sizes, different thicknesses of lines, number of grid lines, type of system feedback, amount of system feedback and presence of a tactile grid pad. Real-time validation is important to the on-going self-awareness during drawing activities. Hence there is a need for new and innovative assistive software for BVI users to overcome the impediment of fear of failure with the use of technology. Haptic validation using mobile phones or hyper braille could be made available for touch feel in future.

Overall, our results confirmed that SETUP09 2D drawing and navigation technique is reliable and efficient, and facilitates the reproduction of accurate mental images. This research suggests a need for a thorough and quick feedback technique with sonification to help BVI individuals with feedback on location, size, shapes, and also a haptic technology for on-screen validation to improve the efficiency of scientific and non-scientific drawing in future. 


\section{References}

Apple, A. W. (2002). Modern Compiler Implementation in Java (2nd Ed.).

New York, NY, USA: Cambridge University Press.

B.Gould \& Ferrell, K. (2009). Accessible science: how to describe stem images. AER Journal.

Blenkhorn, P. \& Evans, D. G. (1998). Using speech and touch to enable blind people to access schematic diagrams. Journal of Network and Computer Applications, 21(1), 17-29.

Bornschein, J. \& Weber, G. (2017). Digital drawing tools for blind users: A state-of-the-art and requirement analysis. In Proceedings of the 10th International Conference on Pervasive Technologies Related to Assistive Environments (pp. 21-28). Island of Rhodes, Greece:ACM.

Buzzi, M. C., Buzzi, M., Leporini, B. \& Senette, C. (2015). Playing with geometry: a multimodal android app for blind children. In CHItaly (pp. 2830). Rome, Italy.

Calder, M., Cohen, R. F., Landry, J. L. N. \& Skaff, J. (2007). Teaching data structures to students who are blind. In 12th Annual SIGCSE Conference on Innovation and Technology in Computer Science Education, Volume 39 Issue 3. Dundee, Scotland, UK: SIGCSE. 
Cook, A. M. \& Polgar, J. M. (2015). Assistive Technologies Principles and Practice. Mosby.

E. Ricciardi, D. B. (2009). Do we really need vision,? how blind people see the actions of others. The Journal of Neuroscience: The Official Journal of the Society for Neuroscience, 29(31), 9719.

Fujiyoshi, M., Akio, Fujiyoshi, Osawa, A., KurodaYuta, Y. \& Sasaki (2014). Development of synchronized cui and gui for universal design tactile graphics production system bplot3. Computers Helping People with Special, 8548(1825).

Fujiyoshi, M. F. A., Yamaguchi, N. O. K. \& Teshima, Y. (2008). The development of a universal design tactile graphics production system bplot2. In $I C C H P$ (pp. 938-945). Verlag Berlin Heidlberg.

Gardner, J., R.Stewart, J. F., Smith, A. \& Tiger (2002). Agc and wintriangle, removing the barrier to stem education. In CSUN Conference.

Grussenmeyer, W. (2015). Draw and drag: accessible touchscreen geometry for students who are blind. In ACM SIGACCESS Accessibility and Computing (pp. 10-13).

Hersh, M. A., Johnson, M. A. \& Michael, A. (2008). Assistive Technology for Visually Impaired and Blind People. Number 1. Berlin: Springer- Verlag London. 
Huissen (2016). Talking tactile tablet. Technical report, Touch Graphics, Inc, Elkton, Maryland, USA.

Ishihara, T., Takagi, H., Itoh, T. \& Asakaw, C. (2006). Analyzing visual layouts for non-visual presentations - document interface. In Proceedings of the 8th international ACM SIGACCESS conference on Computers and accessibility (pp. 65-172). Portland, Oregon, USA: ACM Press.

Kamel, H. M. \& Landay, J. A. (2000). A study of blind drawing practice: Creating graphical information without the visual channel. In Fifth International ACM Conference on Assistive Technologies (pp. 13-15). Arlington, Virginia: Assets ' 00.

Kamel, H. M. \& Landay, J. A. (2002). Sketching images eyes-free: A grid-based dynamic drawing tool for the blind. In Fifth International ACM Conference on Assistive Technologies, number 33-40. Edinburgh, Scotland: ACM Press.

Kassim, A. M., Yasuno, T., Suzuki, H., H.Jaanfar \& M.Aras (2016). Indoor navigation system based on passive rfid transponder with digital compass for visually impaired people. International Journal of Advanced Computer Science and Applications, 7(2), 604-610.

Kosslyn, S. \& et al, D. O. (1990). Mental imagery. Visual Cognition and Action (pp. 73-97).

Kurniawan, S. H., Sutcliffe, A. G. \& Blenkhorn, P. L. (2003). How blind users 
mental models affect their perceived usability of an unfamiliar screen reader. Human-Computer Interaction-INTERACT'03 (pp. 631-638).

Lambert, S., Sampaio, E., Mauss, Y. \& Scheiber, C. (2004). Blindness and brain plasticity: Contribution of mental imagery? Cognitive Brain Research, 20(1), $1-11$.

Leo, F., Cocchi, E. \& Brayda, L. (October 2016). The effect of programmable tactile displays on spatial learning skills in children and adolescents of different visual disability. IEEE Transactions on Neural Systems and Rehabilitation Engineering, PP.

Games Ltd, I. (2014). If games, 2014.

Meliones, A. \& Sampson, D. (2018). Blind museumtourer: A system for self-guided tours in museums and blind indoor navigation. Technologies, 6(4).

N.Takagi (2009). Mathematical figure recognition for automating production of tactile graphics. In IEEE International Conference on System, Man and Cybernetics (SMC 2009) (pp. 4651-4656). IEEE.

Ohene-Djan, J. F. \& Fernando, S. A. (2018). Screen navigation system for visually impaired people. JOURNAL OF ENABLING TECHNOLOGIES, 12(3), 114-128.

School Perkins (2019). Art in science: Tools for drawing for students with visual impairment. 
Petrie, H., Schlieder, C., Blenkhorn, P., Evans, G., A. King, A. M. O., Ioannidis, G. T., Gallagher, B., D. Crombie, R. M. \& Alafaci, M. (2002). Tedub: A system for presenting and exploring technical drawings for blind people. In 8th International Conference ICCHP, Volume 2398. Linz, Austria: ACM Press.

Pinker, S. (1984). Visual cognition. MIT Press.

Rassmus-Grohn, K., Magnusson, C. \& Efiring, H. (2007). Ahead - audio-haptic drawing editor and explorer for education. In IEEE International Workshop on Haptic Audio Visual Environments and their Applications. Ottawa, Canada: IEEE.

Silva, C. \& Wimalaratne, P. (2017). Towards a grid based sensor fusion for visually impaired navigation using senor and vision measurements. IEEE Humanitarian Technology Conference.

Walker, B. N. \& Mauney, L. M. (March 2010). Universal design of auditory graphs: A comparison of sonification mappings for visually impaired and sighted listeners. ACM Transactions on Accessible Computing (TACCESS), Volume 2 Issue 3.

Williams, G. J., Zhang, T., Lo, A., Gonzales, A. \& D. Baluch, B. D. (2014). 3d printing tactile graphics for the blind: Application to histology. In Annual 
Rehabilitation Engineering Society of North America Conference 2014. Indianapolis,IN.

Withagen, A., Kappers, A. M., Vervloed, M. P., Knoors, H. \& Verhoeven,

L. (2013). Short-term memory and working memory in blind versus sighted children. Research in Developmental Disabilities, 34, 2161- 2172.

Zhang, T., Duerstock, B. S. \& Wachs, J. P. (February 2017). Multimodal perception of histological images for persons who are blind or visually impaired. ACM Transactions on Accessible Computing (TACCESS), Volume 9 Issue 3.

Zhu, S. \& Feng, J. (2010). Investigating grid-based navigation: The impact of physical disability. ACM Transaction on Accessible Computing, 3(1).

\section{Funding}

This research received no specific grant from any funding agency in the public, commercial, or not-for-profit sectors.

\section{Declaration of conflicting interests}

The authors declare no potential conflict of interests with respect to the research, authorship, and/or publication of this article.

\section{Copyright}

Copyright 2019 SAGE Publications Ltd, 1 Oliver's Yard, 55 City Road, London, EC1Y 1SP, UK. All rights reserve 


\section{Notes}

${ }^{\mathrm{i}}$ InTACT SketchPad creates tactile graphics by using a stylus; a raised line appears under your fingertip.

${ }^{i i}$ Sensational Blackboard enables to create tactile pictures, the person draw without flipping the paper over, no need to draw reverse.

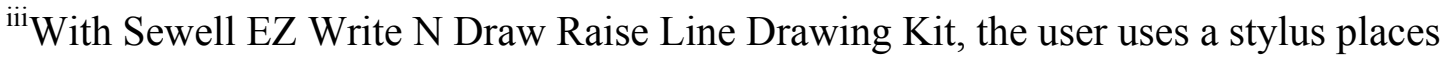
sheet of tracing material, foil over rubber-faced clipboard. Raised tactile picture can be felt on reverse side of the page.

iv Tactipad enables user to make tactile drawing by hand, firmly pressing down on the foil with the pen to get raise lines with tactile image.

${ }^{v}$ Swai Dot Inverter uses specially made stylus to invert a series of single dots placed on top of the rubber pad. "The special stylus allows dots to be embossed upwards by puncturing the paper on the down stroke and then pulling the dot upwards on the up stroke." htps://www.aph.org/?s=Swail+Dot+Inverter:

vi “Quick Draw paper is convenient for use on the go. Water-based markers or paintbrushes with water cause the lines of the image created to swell from the paper." https://www.aph.org/?s=Quick+Draw+Paper+ 